\title{
In vitro cytotoxicity of oxide nanoparticles: Comparison to asbestos, silica and the effect of particle solubility
}

Tobias J. Brunner ${ }^{1}$, Peter Wick ${ }^{2}$, Pius Manser ${ }^{2}$, Philipp Spohn ${ }^{2}$, Robert N. Grass ${ }^{1}$, Ludwig K. Limbach ${ }^{1}$, Arie Bruinink ${ }^{2}$, Wendelin J. Stark ${ }^{1, *}$

${ }^{1}$ Institute for Chemical and Bioengineering, Department of Chemistry and Applied Biosciences, ETH Zurich, CH-8093 Zurich, Switzerland

${ }^{2}$ Laboratory for Biocompatible Materials, EMPA Materials Science and Technology, Lerchenfeldstrasse 5, CH-9014 St. Gallen, Switzerland

\section{Supporting Information}

* To whom correspondence should be addressed:

Wendelin J. Stark

Institute for Chemical and Bioengineering, HCI E 107

ETH Hoenggerberg

Wolfgang-Pauli-Str. 10

CH-8093 Zurich

Switzerland

e-mail: wendelin.stark@ chem.ethz.ch

phone: +41446320980

fax: $\quad+41446331083$ 


\section{Materials and Methods.}

Nanoparticle preparation and dispersion. Nanoparticles were prepared by flame spray synthesis using metals dissolved in 2-ethylhexanoic acid as precursors (see Figure 1, right) $(1,2)$. A more detailed description of the flame spray process and set-up is given by Loher et al. (3). As-prepared nanoparticles (Figure 1, left) were dry-heat sterilized for 3 hours at $160^{\circ} \mathrm{C}$ and dispersed in ultra-pure water (Millipore, resistivity $>18 \mathrm{M} \Omega \mathrm{cm}^{-1}$ ) to prepare stock dispersions of 1000 parts per million (ppm, corresponds to $\mu \mathrm{g}$ particles per ml cell culture medium; further referred to as $\mathrm{ppm}$ ). Dispersions were sonicated for $10 \mathrm{~min}$ in an ultra-sound bath (600 Watt, Sonorex RK $156 \mathrm{BH}$, Bandelin) to break up agglomerates and diluted to the final exposure concentrations with cell culture medium (see below) prior to application. Crocidolite $\left(\mathrm{Na}_{2}(\mathrm{Fe}, \mathrm{Mg})_{5} \mathrm{Si}_{8} \mathrm{O}_{22}(\mathrm{OH})_{2}\right)$ asbestos was donated by the National Research Institute for Occupational Diseases (Johannesburg, South Africa). The size distribution and chemical composition are given in Table S1 and S2.

Table S1. Size distribution of crocidolite asbestos fibers.

\begin{tabular}{lccccc}
\hline \multicolumn{7}{c}{$\%$ of fibers (by number) } \\
Length $/ \mu \mathrm{m}$ & $3-5$ & $5-10$ & $10-25$ & $25-50$ & $>50$ \\
\hline Crocidolite & 53.8 & 36.0 & 9.2 & 1.0 & 0.1 \\
\hline
\end{tabular}

Table S 2. Transition metal content of crocidolite asbestos fibers.

\begin{tabular}{lllllc}
\hline & \multicolumn{5}{l}{ Element content / wt $\%$} \\
Element: & $\mathrm{Fe}$ & $\mathrm{Ni}$ & $\mathrm{Cr}$ & $\mathrm{Co}$ & $\mathrm{Mn}$ \\
\hline Crocidolite & 15.1 & 0.0013 & 0.0022 & 0.0009 & 0.0864 \\
\hline
\end{tabular}

Nanoparticle characterization. The specific surface area (SSA) of the as-synthesized nanopowders was measured on a Tristar (Micromeritics Instruments) instrument by nitrogen adsorption at $77 \mathrm{~K}$ using the Brunauer-Emmett-Teller (BET) method with samples outgassed at $150{ }^{\circ} \mathrm{C}$ for 1 hour prior to 
analysis. The average BET-equivalent particle diameter $d_{\text {BET }}$ was calculated using $d_{\text {BET }}=$

6/(SSA $\rho$ ), where $\rho$ denotes the density $\left(\mathrm{kg} \mathrm{m}^{-3}\right)$, assuming monodisperse particles (see Table 1). X-ray powder diffraction (XRD) patterns were collected on a Bruker D 8 Advance diffractometer from $15^{\circ}$ to $50^{\circ}$ at a step size of $0.12^{\circ}$ and a scan speed of $2.4^{\circ} \mathrm{min}^{-1}$ at ambient condition to confirm identity and crystallinity of materials (4). Mean crystallite diameters were calculated according to the Scherrer equation (5) as an additional measurement of crystallite size. Particle shape and morphology were investigated by transmission electron microscopy (TEM) recorded on a CM30 ST (Philips, LaB6 cathode, operated at $300 \mathrm{kV}$, point resolution $2 \AA$ ). Full particle size analyses were measured by X-ray disc centrifugation (XDC, Brookhaven Instruments, instrumental cutoff below $5 \mathrm{~nm}$ ). Prior to measurements particles were dispersed in ultrapure water (Millipore, resistivity $>18 \mathrm{M} \Omega \mathrm{cm}^{-1}$ ) and stabilized with Dispex A40 (Ciba Specialty Chemicals). After 5 minutes of sonication (Hielscher UP400S) the hydrodynamic particle diameter was measured on an X-ray disc centrifuge.
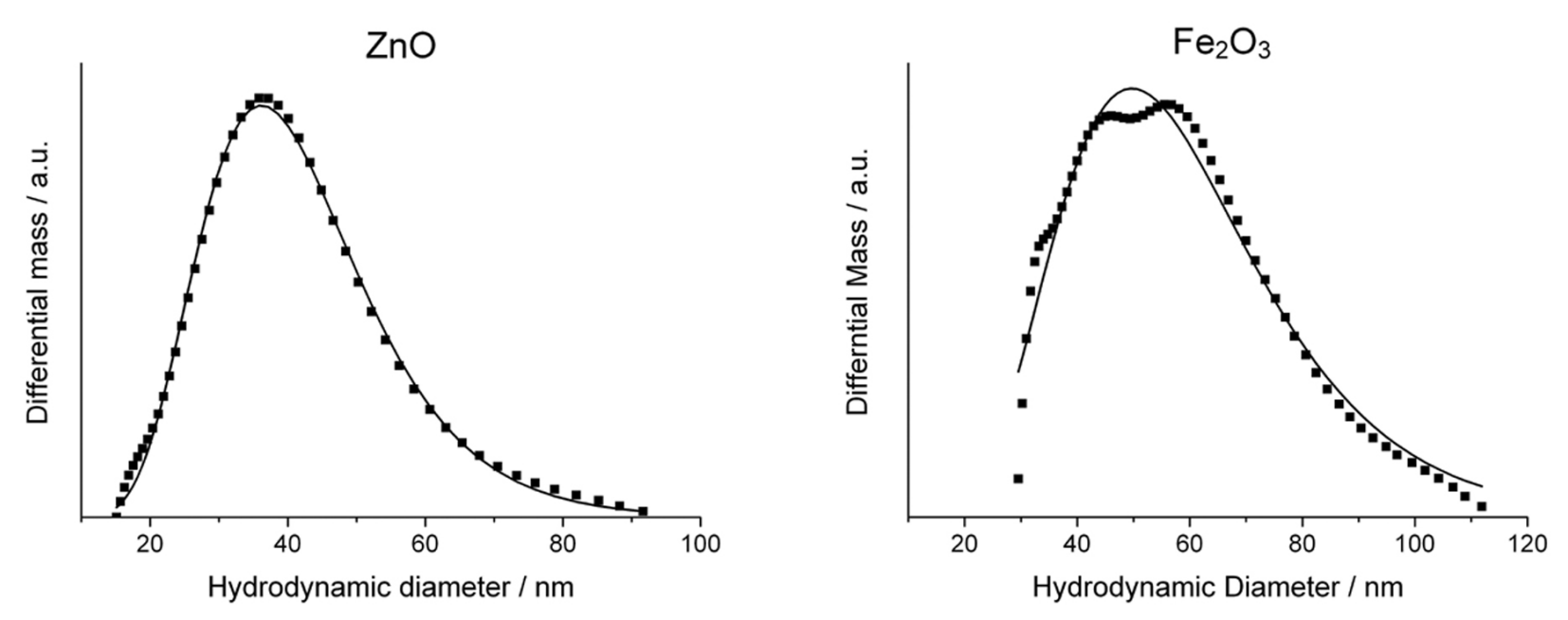

Figure S1. Particle size distribution of zinc and iron oxide as dispersions in water. Comparison of measured (squares) and calculated (line) distribution corroborates a log-normal distribution which can be well described by a mean diameter and a geometric standard deviation $\sigma_{\mathrm{g}}$. 
Cell culture and exposure to nanoparticles. Mesothelioma cells MSTO-211H (ATCC, Manassas, VA, USA; CRL-2081), further referred to as MSTO, were cultivated in T25 flasks (TTP, Trasadingen, Switzerland) with RPMI-1640 medium (Sigma-Aldrich, Buchs, Switzerland) containing 10\% fetal calf serum (Invitrogen AG, Basel, Switzerland) and 1\% penicillin-streptomycin-neomycin antibiotic mixture (PSN, $5 \mathrm{mg} \mathrm{mL}^{-1}$ penicillin, $5 \mathrm{mg} \mathrm{mL}^{-1}$ streptomycin, and $10 \mathrm{mg} \mathrm{mL}^{-1}$ neomycin, Invitrogen AG, Basel, Switzerland) at $37^{\circ} \mathrm{C}$ in a humidified atmosphere of $5 \% \mathrm{CO}_{2} / 95 \%$ air. Before exposure experiments, cells near confluence were trypsinized and transferred into 24-well cultivation (TRP) plates. After 1 day in culture, the medium was replaced by $1 \mathrm{~mL}$ fresh medium containing the appropriate concentrations of nanoparticles. As a second cell type 3T3 Swiss Albino mouse fibroblasts (ECACC, Salisbury, UK; Nr. 85022108) were cultivated in D-MEM (Gibco) containing 10\% fetal calf serum (Invitrogen AG, Basel, Switzerland), $2 \mathrm{mM}$ L-Glutamine (bioconcept) and antibiotics as described for MSTO cells. For the 3 or 6 day exposure experiments, 3000 or 1500 MSTO cells per milliliter were used in the 24 wellplates. In the case of slower proliferating 3T3 cells 9000 or 4500 cells per milliliter were used, respectively. Cells were exposed to $7.5,15$ and $30 \mathrm{ppm}$ nanoparticles for 3 days or to $3.75,7.5$ and 15 ppm for 6 days. Before and after exposure to nanoparticles, both MSTO and 3T3 cells were observed under a Nikon Diaphot light microscope combined with a digital imaging analysis system (Nikon Coolpix 995).

In vitro cytotoxicity. A thiazolylblue tetrazolium bromide (MTT) assay (6-9) was applied to colorimetrically measure the mean cell culture cell activity according to Bruinink et al. (10). Upon addition of $125 \mu \mathrm{L}$ MTT (3-(4,5-dimethylthiazol-2-yl)-2,5-diphenyltetrazolium bromide) solution (5 $\mathrm{mg} \mathrm{mL} \mathrm{m}^{-1}$ ) and incubation for one hour, the supernatant was disposed. The blue formazan product was then dissolved in $0.5 \mathrm{~mL}$ ethanol $(90 \%)$ on a horizontal shaker. Absorbance measurements at $550 \mathrm{~nm}$ (Bio-Tek Instruments ELx800) were carried out after all MTT-formazan was dissolved (10 min). The 
relative cell culture activity (\%) related to cultures without exposure to nanoparticles was calculated by $\left[\mathrm{A}_{\text {testt }} /\left[\mathrm{A}_{\text {ctrl }}\right] \times 100\right.$, where $\mathrm{A}$ denotes the absorbance at $550 \mathrm{~nm}$.

The number of cells was assessed taking the amount of DNA per well as an index and quantified using a fluorometric DNA assay (11). The fluorescence of the Hoechst 33258 reagent is enhanced after binding specifically to DNA and therefore allows a spectroscopical quantification of the DNA content after cell lysis. For analysis, the supernatant of the corresponding cell culture was removed after 3 or 6 days exposure and treated hypotonically with $250 \mu \mathrm{L}$ Millipore water during one hour. After lysis, 250 $\mu$ L Hoechst 33258 staining (Sigma-Aldrich, Buchs, Switzerland) solution was then added to the wells and incubated for one hour. The resulting fluorescence was measured at $460 \mathrm{~nm}$ on a fluorescence reader (FLx800, Bio-Tek) with excitation at $350 \mathrm{~nm}$. DNA quantity was determined using calf thymus DNA (Sigma-Aldrich, Buchs, Switzerland, D3664) as a standard. The relative amount of DNA (\%) compared to cultures without exposure to nanoparticles was calculated by $\left[\mathrm{F}_{\text {test }} /\left[\mathrm{F}_{\text {ctrl }}\right] \times 100\right.$, where $\mathrm{F}$ is the fluorescence signal strength at $460 \mathrm{~nm}$.

Statistics. All assays were carried out using five experiments in parallel using identically treated and processed cultures and performed in at least 3 independent series of experiments. For all figures MTT conversion rate and DNA culture content data were represented as (mean values \pm standard error of the mean values) over (mean experimental values) relative to untreated controls. Effects of the various nanoparticles on the cell cultures were statistically analyzed with a $p<0.05$ significance level using a two-factorial Bonferroni/Dunn analysis of variance test taking experiment number and nanoparticle concentrations as factors. 


\section{References}

(1) Madler, L.; Kammler, H.; Mueller, R.; Pratsinis, S. Controlled synthesis of nanostructured particles by flame spray pyrolysis. J. Aerosol Sci. 2002, 33, 369-389.

(2) Stark, W. J.; L., M.; Pratsinis, S. E., WO 2004/005184.

(3) Loher, S.; Stark, W. J.; Maciejewski, M.; Baiker, A.; Pratsinis, S. E.; Reichardt, D.; Maspero, F.; Krumeich, F.; Günther, D. Fluoro-apatite and calcium phosphate nanoparticles by flame synthesis. Chem. Mater. 2005, 17, 36-42.

(4) Stark, W. J.; Wegner, K.; Pratsinis, S. E.; Baiker, A. Flame aerosol synthesis of vanadia-titania nanoparticles: Structural and catalytic properties in the selective catalytic reduction of NO by NH3. $J$. Catal. 2001, 197, 182-191.

(5) Borchert, H.; Shevehenko, E. V.; Robert, A.; Mekis, I.; Kornowski, A.; Grubel, G.; Weller, H. Determination of nanocrystal sizes: A comparison of TEM, SAXS, and XRD studies of highly monodisperse COPt3 particles. Langmuir 2005, 21, 1931-1936.

(6) Mosmann, T. Rapid colorimetric assay for cellular growth and survival: Application to proliferation and cytotoxicity assays. J. Immunol. Methods 1983, 65, 55-63.

(7) Liu, Y.; Peterson, D. A.; Kimura, H.; Schubert, D. Mechanism of Cellular 3-(4,5Dimethylthiazol-2-yl)-2,5-Diphenyltetrazolium Bromide (MTT) Reduction. J. Neurochem. 1997, 69, 581-593.

(8) Cardoso, S. M.; Santos, S.; Swerdlow, R. H.; Oliveira, C. R. Functional mitochondria are required for amyloid beta-mediated neurotoxicity. FASEB J. 2001, 15.

(9) Berridge, M. V.; Tan, A. S. Characterization of the Cellular Reduction of 3-(4,5-

Dimethylthiazol-2-Yl)-2,5-Diphenyltetrazolium Bromide (MTT) - Subcellular-Localization, Substrate Dependence, and Involvement of Mitochondrial Electron-Transport in Mtt Reduction. Arch. Biochem. Biophys. 1993, 303, 474-482.

(10) Bruinink, A.; Reiser, P. Ontogeny of Map2 and Gfap Antigens in Primary Cultures of Embryonic Chick Brain - Effect of Substratum, Oxygen-Tension, Serum and Ara-C. Int. J. Dev. Neurosci. 1991, 9, 269-279.

(11) Labarca, C.; Paigen, K. Simple, Rapid, and Sensitive DNA Assay Procedure. Anal. Biochem. 1980, 102, 344-352. 